\title{
Clinical and microbiological evaluations of acute periodontitis in areas of teeth applied with orthodontic bands
}

\author{
Kiyoko Tamura*1, Kazuhiko Nakano*1, Sonoko Miyake*1, \\ Atsuko Takada*2 and Takashi Ooshima*1 \\ *1 Department of Pediatric Dentistry, Osaka University Graduate School of Dentistry \\ 1-8 Yamada-oka, Suita, Osaka 565-0871, JAPAN \\ *2 Takada Dental Clinics \\ 2-8-21 Tenno, Ibaraki, Osaka 567-0876, JAPAN
}

\begin{abstract}
Two cases with severe periodontal inflammation in areas of teeth applied with orthodontic bands are presented. Both were diagnosed as acute periodontitis, and removal of the orthodontic bands followed by professional oral hygiene procedures resulted in the recovery to the normal level of periodontal condition. The presence of 10 targeted species of Gram-negative periodontal bacteria in subgingival plaque samples taken from the corresponding teeth, which were not detected in either patient during the period of severe periodontal inflammation, was assessed several times using a polymerase chain reaction method. As the periodontal conditions of the patients improved, these bacteria were identified during the follow-up examination periods. Our results suggest that none of the $10 \mathrm{Gram}$-negative periodontal bacteria were associated the acute periodontitis at the teeth applied with orthodontic bands.
\end{abstract}

\section{Key words}

Acute periodontitis, Orthodontic band, Periodontal bacteria, Polymerase chain reaction

\section{Introduction}

Orthodontic bands are commonly used for the treatment of malocclusion, though they are also often associated with gingival inflammation ${ }^{1}$. Various reasons for such periodontal reactions to orthodontic bands, including subgingival plaque accumulation, mechanical irritation due to subgingival band extension, and cytotoxic effects of the cement and/or band material, have been presented ${ }^{2}$. Above all, insertion of the band is considered to be a crucial factor for establishment of the disease, by changing the subgingival ecological system, which may promote pathogenic periodontal destruction.

We previously surveyed the occurrence of 10 periodontal bacteria in periodontally healthy children $^{3,4)}$, and also performed longitudinal monitoring

Received on February 15, 2005

Accepted on May 23, 2005 of those 10 bacteria in cases of the acute occurrence of localized periodontitis ${ }^{5)}$, and accidentally induced periodontitis ${ }^{6}$. In the present study, we present 2 patients with acute periodontitis, identified around teeth being treated with orthodontic bands, with focus on the correlation between clinical findings and detection of the same 10 periodontal bacteria.

\section{Case Reports}

\section{Case 1}

An 11-year-2-month-old boy, who had been receiving orthodontic treatment for 1 year and 10 months, was referred to the Pedodontic Clinic of Osaka University Dental Hospital for treatment of gingival swelling around the mandibular left first permanent molar. An intraoral examination revealed that the marginal gingiva around the affected tooth was severely swollen with apparent redness (Fig. 1a), as well as severe occlusal pain. The maximum periodontal 
depth was $9 \mathrm{~mm}$ in the disto-buccal area, and the affected tooth showed severe mobility. According to the orthodontist, an orthodontic band had been applied to the affected tooth at the age of 9 years 4 months, and then removed the day before the visit to our hospital. Neither the boy or his immediate family members showed any systemic problems.

A radiographic examination showed alveolar bone loss on the distal side and we made a diagnosis of acute periodontitis. Irrigation of the marginal gingiva, along with general administrations of antibiotics, were carried out, as well as routine professional tooth cleaning with a shorter than normal interval between sessions. Twelve days after the first visit, inflammation of the gingival area had diminished and the maximum periodontal pocket was reduced to $6 \mathrm{~mm}$ (Fig. 1b). One month later, mobility of the affected tooth had disappeared and the maximum periodontal pocket was reduced to $4 \mathrm{~mm}$. Further, bleeding on probing had stopped and the maximum periodontal pocket was reduced to $3 \mathrm{~mm}$ at an examination 3 months later (Fig. 1c), while a periapical radiograph image showed alveolar bone refilling. Periodical examinations have been carried out at 3 month intervals over the last 4 years, and presently there are no signs or symptoms in the area of the affected tooth.

\section{Case 2}

A 2-year-10-month-old girl came to our clinic for treatment of decayed teeth. After treatment for dental caries had been completed, periodical examinations were carried out with intervals of 3 to 4 months. According to the orthodontist, orthodontic treatment for an anterior crossbite had been initiated at the age of 5 years 3 months, after which her oral hygiene became worse. The patient received professional tooth brushing instruction at each of our examinations, during which analysis for the detection of periodontal bacteria in dental plaque or saliva samples was sometimes carried out.

At 7 years 10 months, there were no abnormal signs or symptoms observed at the periodical examination, however, 1 month later the patient returned to our clinic complaining of enlargement of the gingival tissue in the area of the maxillary left second primary molar, where an orthodontic band had been applied. We diagnosed the case as acute periodontitis and the orthodontic appliance was removed, followed by irrigation and antibiotics administration. One week later, the gingival condition was improved and at the age of 8 years 0 months, the gingival conditions were significantly better. Thereafter, routine professional tooth cleaning was a)
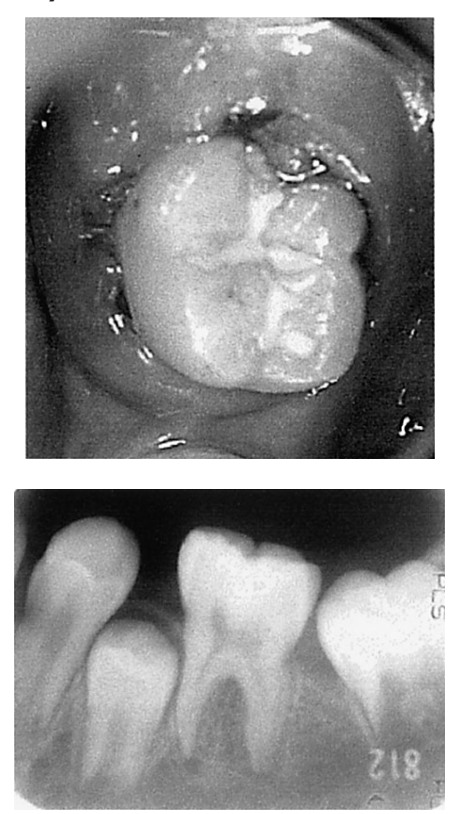

b)
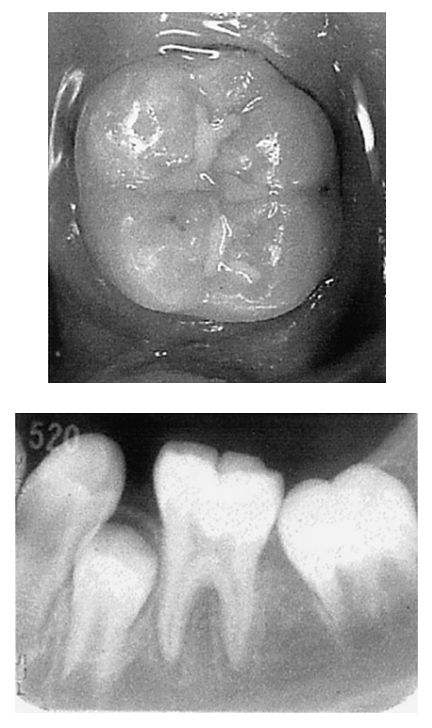

c)
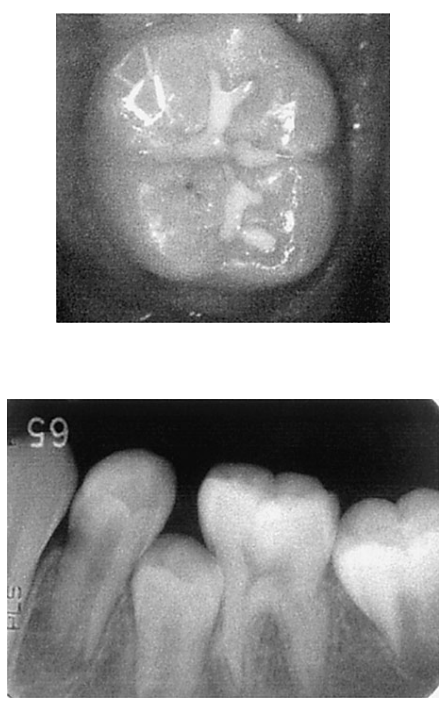

Fig. 1 Intraoral photographs and periapical radiographs from Case 1

a) First visit b) Twelve days after first visit c) Ninety-eight days after first visit 
performed with a shorter interval than normal between sessions, with no abnormal signs identified over the following 4 years.

\section{Clinical examinations}

The clinical parameters examined were probing depth, bleeding on probing, pus discharge, tooth mobility, plaque index ${ }^{7)}$, and gingival index ${ }^{8)}$. Pocket depth was measured to the nearest millimeter at 6 points around the circumference of each tooth (mesio-, mid-, and disto-buccal; and disto-, mid-, and mesio-lingual) from the gingival margin to the deepest probing point, using a round-ended probe tip $0.4 \mathrm{~mm}$ in diameter. Bleeding on probing was scored as follows; $(+)$ immediate bleeding on probing, or $(-)$ no bleeding. Tooth mobility was scored as follows; (2) moderate mobility (1-2 mm) in a buccolingual direction and (1) slight mobility $(0.2-1 \mathrm{~mm})$ in a bucco-lingual direction, or (0) physiological mobility within $0.2 \mathrm{~mm}$. Pus discharge was scored as follows; $(+)$ spontaneous pus discharge, or $(-)$ no pus discharge.

\section{Microbiological examinations}

Microbiological examinations were performed mul- tiple times for both cases using a polymerase chain reaction (PCR) assay, as described previously ${ }^{4)}$. Subgingival plaque was collected from the mandibular left first permanent molar in Case 1 and maxillary left second primary molar in Case 2 with sterile Gracey curettes, after gently removing supragingival plaque, then the samples were suspended in $1 \mathrm{ml}$ of sterile saline, and centrifuged at 15,000 rpm for 5 minutes to pellet the bacterial cells. Bacterial genomic DNA was then isolated from the pellet using a DNA isolation kit (Puregene, Gentra Systems, Minneapolis, MN, USA).

The following Gram-negative anaerobic bacterial species were selected, based on a list of putative periodontal pathogens: Porphyromonas gingivalis, Treponema denticola, Capnocytophaga ochracea, Capnocytophaga sputigena, Prevotella intermedia, Prevotella nigrescens, Campylobacter rectus, Actinobacillus actinomycetemcomitans, Tannerella forsythensis, and Eikenella corrodens. Table 1 shows the species-specific PCR primers selected for use in the present study, which have been described previously ${ }^{9-13}$. A ubiquitous primer set that matches nearly all bacterial 16S rRNA genes was used as a positive control. The PCR amplifications were

Table 1 PCR primer sets

\begin{tabular}{|c|c|c|c|c|}
\hline Primer set & Sequence $\left(5^{\prime}\right.$ to $\left.3^{\prime}\right)$ & Size (bp) & $\begin{array}{l}\text { Annealing } \\
\text { temperature }\left({ }^{\circ} \mathrm{C}\right)\end{array}$ & Reference \\
\hline $\begin{array}{l}\text { Universal primer } \\
\text { (positive control) }\end{array}$ & $\begin{array}{l}\text { AGA GTT TGA TCM TGG CTC AG } \\
\text { CTG CTG CSY CCC GTA G }\end{array}$ & 315 & 55 & 9 \\
\hline P.gingivalis & $\begin{array}{l}\text { TGT AGA TGA CTG ATG GTG AAA ACC } \\
\text { ACG TCA TCC CCA CCT TCC TC }\end{array}$ & 197 & 60 & 10 \\
\hline T. denticola & $\begin{array}{l}\text { AAG GCG GTA GAG CCG CTC A } \\
\text { AGC CGC TGT CGA AAA GCC CA }\end{array}$ & 311 & 55 & 11 \\
\hline C. ochracea & $\begin{array}{l}\text { AGA GTT TGA TCC TGG CTC AG } \\
\text { GAT GCC GTC CCT ATA TAC GGG G }\end{array}$ & 185 & 55 & 12 \\
\hline C. sputigena & $\begin{array}{l}\text { AGA GTT TGA TCC TGG CTC AG } \\
\text { GAT GCC GCT CCT ATA TAC CAT TAG G }\end{array}$ & 185 & 55 & 12 \\
\hline P. intermedia & $\begin{array}{l}\text { TTT GTT GGG GAG TAA AGC GGG } \\
\text { TCA ACA TCT CTG TAT CCT GCG T }\end{array}$ & 575 & 55 & 13 \\
\hline P.nigrescens & $\begin{array}{l}\text { ATG AAA CAA AGG TTT TCC GGT AAG } \\
\text { CCC ACG TCT CTG TGG GCT GCG A }\end{array}$ & 804 & 55 & 13 \\
\hline A. actinomycetemcomitans & $\begin{array}{l}\text { AGA GTT TGA TCC TGG CTC AG } \\
\text { CAC TTA AAG GTC CGC CTA CGT GCC }\end{array}$ & 593 & 60 & 12 \\
\hline T. forsythensis & $\begin{array}{l}\text { GCG TAT GTA ACC TGC CCG CA } \\
\text { TGC TTC AGT GTC AGT TAT ACC T }\end{array}$ & 641 & 60 & 13 \\
\hline C. rectus & $\begin{array}{l}\text { TTT CGG AGC GTA AAC TCC TTT TC } \\
\text { TTT CTG CAA GCA GAC ACT CTT }\end{array}$ & 598 & 60 & 13 \\
\hline E.corrodens & $\begin{array}{l}\text { CTA ATA CCG CAT ACG TCC TAA G } \\
\text { CTA CTA AGC AAT CAA GTT GCC C }\end{array}$ & 688 & 60 & 13 \\
\hline
\end{tabular}


a) $\mathrm{M} P C \mathrm{Pg} \mathrm{Td}$ Co $\mathrm{Cs} \mathrm{Pi} \mathrm{Pn} \mathrm{Aa}$ Tf $\mathrm{Cr}$ Ec M

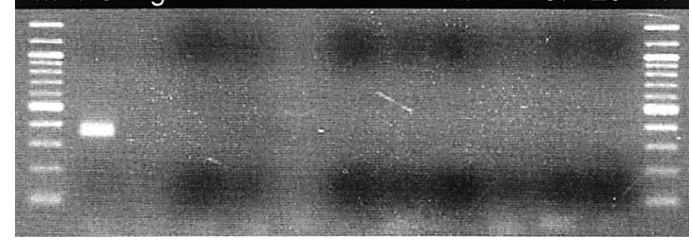

b) M PC Pg Td Co Cs Pi Pn Aa Tf Cr Ec M

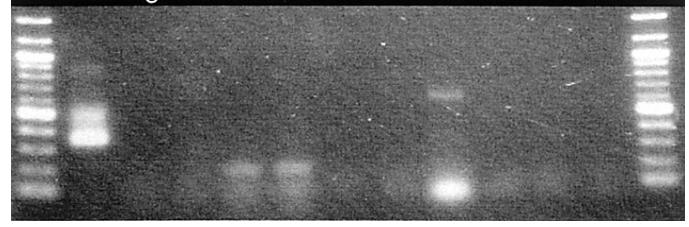

c) M PC Pg Td Co Cs Pi Pn Aa Tf Cr Ec M

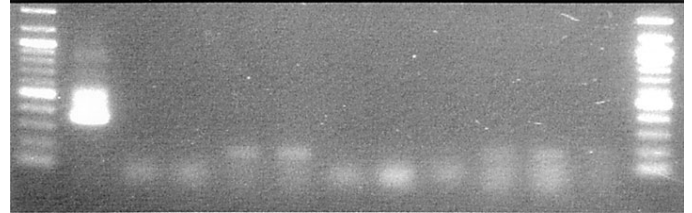

Fig. 2 PCR detection of the periodontopathic bacteria in Case 1

a) First visit b) Twelve days after first visit

c) Ninety-eight days after first visit

M: 100-bp ladder, PC: positive control, Pg: P. gingivalis,

Td: T.denticola, Co: C.ochracea, Cs: C. sputigena,

Pi: P. intermedia, Pn: P.nigrescens,

Aa: A.actinomycetemcomitans, Tf: T.forsythensis,

Cr: C.rectus, Ec: E.corrodens performed in a reaction mixture containing PCR beads (Ready-To-Go; Amersham Pharmacia Biotech, Piscataway, NJ, USA).

\section{Results}

Table 2 shows the transitional changes of periodontal condition and presence of bacteria in Case 1. At the first visit, when the affected tooth showed severe inflammation with mobility, none of the 10 tested bacterial species could be identified. As the periodontal condition improved, some of the tested bacterial species, including C.ochracea, C. sputigena, and A.actinomycetemcomitans, were detected at 5 and 12 days after the first visit (Fig. 2), and only A. actinomycetemcomitans was detected at 30 days. At 98 days and thereafter, bleeding on probing was not observed, and the maximum periodontal pocket depth was reduced to $3 \mathrm{~mm}$. The number of detected bacterial species was 2 at 98 days and 3 at 147 days in plaque samples, while at 217 days, 7 out of 10 bacterial species, including T.forsythensis, and P. nigrescens, were identified in plaque samples.

As for Case 2, the subject, who showed localized aggressive periodontitis at the site of the tooth being

Table 2 Longitudinal changes in periodontal bacteria in subgingival plaque from the mandibular left first molar of Case 1

\begin{tabular}{lccccccc}
\hline & \multicolumn{7}{c}{ Days after acute attack } \\
\cline { 2 - 7 } & 0 & 5 & 12 & 30 & 98 & 147 & 217 \\
\hline Gram-negative anaerobic bacteria & & & & & & & \\
$\quad$ P. gingivalis & - & - & - & - & - & - & - \\
T. denticola & - & - & - & - & - & - & - \\
C.ochracea & - & + & + & - & + & - & + \\
C.sputigena & - & + & + & - & + & - & + \\
P.intermedia & - & - & - & - & - & - & - \\
P.nigrescens & - & - & - & - & - & + & + \\
A. actinomycetemcomitans & - & + & + & + & - & + & + \\
T.forsythensis & - & - & - & - & - & - & + \\
C.rectus & - & - & - & - & - & - & + \\
E.corrodens & - & - & - & - & - & + & + \\
Periodontal condition & & & & & & & \\
Pocket depth (mm) & 9 & 7 & 6 & 4 & 3 & 2 & 3 \\
Bleeding on probing & + & + & + & + & - & - & - \\
Gingival index & 2 & 1 & 1 & 1 & 1 & 1 & 1 \\
Plaque index & 0 & 1 & 1 & 2 & 1 & 1 & 1 \\
Mobility & 3 & 1 & 1 & 0 & 0 & 0 & 0 \\
Pus exudate & - & - & - & - & - & - & - \\
\hline
\end{tabular}


treated with an orthodontic band, was routinely monitored for the presence of periodontal bacteria, with the longitudinal record shown in Table 3. There was no abnormal periodontal condition seen at 7 years 10 months. The onset of periodontitis at the maxillary left second primary molar was estimated to begin between 7 years 10 months and 7 years 11 months, though at 7 years 11 months none of the 10 tested periodontal bacteria could be identified. At the next visit at 8 years 0 months old, the periodontal condition was unchanged, however, 7 of the bacterial species were identified in plaque samples, while at 8 years 4 months, 8 species were detected in plaque samples, among which were $P$. gingivalis and T.forsythensis. At that time, bleeding on probing was not observed and the periodontal condition was slightly better as compared to that at 8 years 0 months.

\section{Discussion}

We previously presented a case of acute occurrence of localized aggressive periodontitis with rapid alveolar bone loss and refill in a 10-year-old girl'5), which was somewhat similar to the 2 present cases of acute periodontitis in regards to clinical and microbiological findings. In the former patient, none of the 10 periodontal bacteria were also detected in the region of the affected tooth with rapid alveolar bone loss and a greater number of species was identified, as the location of alveolar bone loss was refilled ${ }^{5}$. On the other hand, the mean number of those 10 periodontal bacterial species was 3.75 in periodontally healthy children ${ }^{3)}$. Interestingly, as the location of alveolar bone loss was refilled in our former case, a greater number of species was identified.

Acute periodontitis is considered to be caused by an invasion of pyogenic bacteria through pocket epithelium secondary to microtrauma, during which several millimeters of periodontal attachment and alveolar bone can be lost within a few days ${ }^{14)}$. None of the 10 tested periodontal bacteria were detected in dental plaque taken from the affected site in either of the present cases, whereas 2 of those species were found in a saliva sample from Case 2 (data not shown). In addition, the analysis of the plaque samples from the site of orthodontic bands in the 4 cases without acute periodontitis from our previous records showed that any of the 10 periodontal

Table 3 Longitudinal changes in periodontal bacteria in subgingival plaque from the maxillary left second primary molar of Case 2

\begin{tabular}{lcccc}
\hline & \multicolumn{5}{c}{ Patient age } \\
\cline { 2 - 5 } & 7 Y10M & 7 Y11M & $8 Y 0 \mathrm{M}$ & $8 \mathrm{Y} 4 \mathrm{M}$ \\
\hline Gram-negative anaerobic bacteria & & & & \\
P. gingivalis & - & - & - & + \\
T.denticola & - & - & - & - \\
C.ochracea & + & - & + & + \\
C. sputigena & - & - & + & + \\
P.intermedia & - & - & - & - \\
P.nigrescens & - & - & + & + \\
A. actinomycetemcomitans & + & - & + & + \\
T.forsythensis & - & - & + & + \\
C.rectus & + & - & + & + \\
E.corrodens & - & - & + & + \\
Periodontal condition & & & & \\
Pocket depth (mm) & 3 & 4 & 4 & 3 \\
Bleeding on probing & - & + & + & - \\
Gingival index & 1 & 1 & 1 & 1 \\
Plaque index & 2 & 1 & 1 & 1 \\
Mobility & 0 & 0 & 1 & 0 \\
Pus exudate & - & - & - & - \\
\hline
\end{tabular}


bacteria was detected in all of the cases (Case 3 to 6 ; Table 4). Thus, it is possible that pathogenic bacteria associated with the acute periodontitis seen at the sites with orthodontic bands did not include the 10 targeted periodontal bacteria examined. However, accumulation of the data of the detection of periodontopathic bacteria at the site of orthodontic bands in the subjects with or without acute periodontitis should be required to evaluate this hypothesis.

Previous studies have shown that a shift in subgingival microflora occurs soon after band placement, as the population of peri-pathogenic bacteria with anaerobic rods increases, in particular Prevotella and Bacteroides species, fusiform bacteria, and spirochetes ${ }^{1,15)}$. It is speculated that dominant pathogenic bacteria might inhibit the presence of other commonly-identified periodontal bacteria. Surprisingly, the periodontal condition of Case 2 remained unchanged between 7 years 11 months and 8 years 0 months, even though 7 of the 10 targeted bacteria were detected in subgingival plaque samples taken at the later time point, which was completely different from the former time point. Four months later, there were no abnormal signs and symptoms in the area of the affected tooth and periodontal tissue, though 8 of the bacteria species were found in plaque samples, suggesting that the subject might be at risk for the onset of periodontitis in the near future.

Huser et al. ${ }^{1)}$ reported the effects of orthodontic bands on microbiologic and clinical parameters in 10 subjects. After applying orthodontic bands to 2 sites, they tested those as well as 2 other sites free of bands in each patient, and found that plaque index and bleeding scores increased significantly in the banded tooth areas, whereas probing depth remained within normal values. In other studies, application of orthodontic bands resulted in an alteration of bacterial composition, including an increase in the percentage of spirochetes, motile rods, filaments and fusiforms, and a decrease in cocci $^{1,2)}$. Application of an orthodontic band itself does not cause acute periodontitis, as the pathogenic transition is considered to depend on other factors, such as the virulence of periodontal pathogens and immunologic defense mechanisms ${ }^{2)}$.

Since periodontitis did not appear immediately after application of the orthodontic bands and only unilateral teeth were affected in the present cases, we considered that there may have been other crucial factors involved than mechanical impairment of the periodontal tissues. We concluded that an alteration of the bacterial composition, which might have contained unknown pathogens related to

Table 4 Longitudinal changes in periodontal bacteria in subgingival plaque from the sites applied with orthodontic bands in the cases without acute periodontitis

\begin{tabular}{|c|c|c|c|c|c|c|c|c|c|c|c|c|c|c|c|c|c|}
\hline & \multirow[b]{2}{*}{ Age } & \multicolumn{6}{|c|}{ Periodontal condition } & \multicolumn{10}{|c|}{ Gram-negative anaerobic bacteria } \\
\hline & & PD & BOP & GI & PI & Mob & Pus & $\mathrm{Pg}$ & $\mathrm{Td}$ & Co & Cs & $\mathrm{Pi}$ & Pn & $\mathrm{Aa}$ & $\mathrm{Tf}$ & $\mathrm{Cr}$ & Ec \\
\hline \multirow[t]{3}{*}{ Case 3} & $6 \mathrm{Y} 9 \mathrm{M}$ & 3 & - & 0 & 0 & 0 & - & - & - & - & - & - & - & + & - & + & + \\
\hline & $7 \mathrm{Y} 1 \mathrm{M}$ & 3 & - & 0 & 1 & 0 & - & - & - & + & + & - & - & - & - & - & - \\
\hline & $7 \mathrm{Y} 3 \mathrm{M}$ & 2 & - & 0 & 0 & 0 & - & - & - & - & - & - & - & - & - & - & + \\
\hline \multirow[t]{3}{*}{ Case 4} & $8 \mathrm{Y} 2 \mathrm{M}$ & 3 & - & 1 & 1 & 0 & - & - & - & + & - & - & - & - & - & + & - \\
\hline & $8 \mathrm{Y} 7 \mathrm{M}$ & 2 & + & 1 & 1 & 0 & - & - & - & + & + & - & - & + & + & + & + \\
\hline & $8 \mathrm{Y} 11 \mathrm{M}$ & 3 & - & 1 & 2 & 0 & - & - & - & + & + & - & - & + & - & + & - \\
\hline \multirow[t]{3}{*}{ Case 5} & $12 \mathrm{Y} 11 \mathrm{M}$ & 3 & - & 1 & 0 & 0 & - & - & - & + & - & - & - & - & - & - & - \\
\hline & $13 \mathrm{Y} 1 \mathrm{M}$ & 2 & + & 0 & 1 & 0 & - & - & - & - & - & - & - & + & - & - & - \\
\hline & $13 \mathrm{Y} 2 \mathrm{M}$ & 3 & - & 0 & 1 & 0 & - & - & - & + & + & - & + & + & - & - & + \\
\hline \multirow[t]{4}{*}{ Case 6} & $9 \mathrm{Y} \mathrm{7M}$ & 3 & - & 1 & 1 & 0 & - & - & - & - & + & - & - & - & - & - & - \\
\hline & $9 \mathrm{Y} 9 \mathrm{M}$ & 3 & + & 1 & 1 & 0 & - & - & - & - & + & - & - & - & - & - & - \\
\hline & $9 \mathrm{Y} 10 \mathrm{M}$ & 3 & + & 1 & 0 & 0 & - & - & - & - & - & - & + & + & - & - & - \\
\hline & $10 \mathrm{Y} 3 \mathrm{M}$ & 4 & + & 1 & 1 & 0 & - & - & - & - & + & - & - & + & - & - & - \\
\hline
\end{tabular}

PD: Pocket depth (mm), BOP: Bleeding on probing, GI: Gingival index, PI: Plaque index, Mob: Mobility, Pus: Pus exudates, Pg: P. gingivalis, Td: T.denticola, Co: C.ochracea, Cs: C.sputigena, Pi: P.intermedia, Pn: P.nigrescens,

Aa: A.actinomycetemcomitans, Tf: T.forsythensis, Cr: C.rectus, Ec: E.corrodens 
periodontitis, as well as pre-existing systemic factors, may have led to appearance of the disease in the present patients. Accumulation of data from similar cases will help to reveal associated pathogenic bacteria and host factors related to the type of periodontitis seen in the present cases.

\section{Acknowledgments}

This study was supported by a Grant-in-Aid for Scientific Research (B) 16390605 from Japan Society for Promotion of Science, and was a part of 21st Century COE entitled "Origination of Frontier BioDentistry" at Osaka University Graduate School of Dentistry supported by the Ministry of Education, Culture, Sports, Science and Technology of Japan.

\section{References}

1) Huser, M.C., Baehni, P.C. and Lang, R.: Effects of orthodontic bands on microbiologic and clinical parameters. Am J Orthod Dentfacial Orthop 97: 213218, 1990.

2) Diedrich, P., Rudzki-Janson, I., Wehrbein, H. and Fritz, U.: Effects of orthodontic bands on marginal periodontal tissues. A histologic study on two human specimens. J Orofac Orthop 62: 146-156, 2001.

3) Kimura, S., Ooshima, T., Takiguchi, M., Sasaki, Y., Amano, A., Morisaki, I. and Hamada, S.: Periodontopathic bacterial infection in childhood. J Periodontol 73: 20-26, 2002.

4) Ooshima, T., Nishiyama, N., Hou, B., Tamura, K., Amano, A., Kusumoto, A. and Kimura, S.: Occurrence of periodontal bacteria in healthy children: a 2-year longitudinal study. Community Dent Oral Epidemiol 31: 417-425, 2003.

5) Ooshima, T., Takiguchi, M., Tamura, K. and Nishiyama, N.: Clinical and microbiological changes in a child with rapid alveolar bone loss and refill. ASDC J Dent Child 69: 143-147, 2002.

6) Ooshima, T., Nishiyama, N. and Tamura, K.: Accidentally induced periodontitis in primary dentition: longitudinal examinations of periodontal bacteria and clinical conditions. Int J Paediatr Dent 13: 193197, 2003.

7) Silness, J. and Löe, H.: Periodontal disease in pregnancy. II. Correlation between oral hygiene and periodontal condition. Acta Odont Scand 22: 121$135,1964$.

8) Löe, H. and Silness, J.: Periodontal disease in pregnancy. I. Prevalence and severity. Acta Odont Scand 21: 533-551, 1963.

9) Doungudomdacha, S., Rawlinson, A. and Douglas, C.W.: Enumeration of Porphyromonas gingivalis, Prevotella intermedia and Actinobacillus actinomycetemcomitans in subgingival plaque samples by a quantitative-competitive PCR method. $J$ Med Microbiol 49: 861-874, 2000.

10) Tran, S.D. and Rudney, J.D.: Multiplex PCR using conserved and species-specific $16 \mathrm{~S}$ rRNA gene primers for simultaneous detection of Actinobacillus actinomycetemcomitans and Porphyromonas gingivalis. J Clin Microbiol 34: 2674-2678, 1996.

11) Watanabe, K. and Frommel, T.O.: Porphyromonas gingivalis, Actinobacillus actinomycetemcomitans and Treponema denticola detection in oral plaque samples using the polymerase chain reaction. J Clin Periodontol 23: 212-219, 1996.

12) Conrads, G., Mutters, R., Fischer, J., Brauner, A., Lutticken, R. and Lampert, F.: PCR reaction and dotblot hybridization to monitor the distribution of oral pathogens within plaque samples of periodontally healthy individuals. J Periodontol 67: 994-1003, 1996.

13) Ashimoto, A., Chen, C., Bakker, I. and Slots, J.: Polymerase chain reaction detection of 8 putative periodontal pathogens in subgingival plaque of gingivitis and advanced periodontitis lesions. Oral Microbiol Immunol 11: 266-273, 1996.

14) Burgett, F.: Periodontal disease. In: Oral Pathology: Clinico-Pathologic Correlations. (Regezi, J.A. and Sciubba, J.J. eds.) Saunders, Philadelphia, 1989, pp. 503-519.

15) Atack, N.E., Sandy, J.R. and Addy, M.: Periodontal and microbiological changes associated with the placement of orthodontic appliances. A review. $J$ Periodontol 67: 78-85, 1996. 